\title{
AN IN VITRO TECHNIQUE FOR REAGGREGATION OF DISSOCIATED TISSUE IN A CENTRIFUGAL FIELD ${ }^{1,2}$
}

\author{
RAYMOND L. HAYES, JR. ${ }^{3}$ \\ Department of Anatomy, The University of Michigan, Ann Arbor, Mich., U.S.A. \\ Received February 3, 1964
}

\begin{abstract}
A technique for reaggregative studies of previously dissociated cell masses has been utilized recently by Moscona [5-8] and Steinberg [11-13]. The initial massing of cells in that system was not dependent on active cellular movement, but on the rotation of the culture vessel and consequent generation of a centripetal force in the cell suspension. Under these conditions, cells were found to be centralized in the culture vessel and to form multiple spheroid aggregates which exhibit tissue patterns resembling those of the in vivo parent morphology.

In the present investigation, a unique cultivation method has been utilized in which the net force generated in the culture medium was centrifugal. In contrast to the centripetal system, this force would tend to peripheralize cells maintained in suspension. The aim of this study was to determine whether cellular aggregability could be effected in a centrifugally-rotating system; if so, concomitant application of these two suspension techniques would provide a tool for analyzing the role of environmental forces in the determination of aggregate morphology.
\end{abstract}

\section{METHODS}

Centrifugal aggregation was achieved in a modified microspinner flask (Bellco) as shown in Fig. 1. The culture vessel was assembled and the cap port sealed with a

\footnotetext{
1 Supported by U.S. Public Health Service Grants 2G-312 (R1; C1) and AM 06918 administered by the Department of Anatomy, The University of Michigan and by Dr Raymond $H$. Kahn, respectively.

${ }^{2}$ Submitted in partial fulfillment of the requirements for the Doctor of Philosophy degree in the School of Graduate Studies, The University of Michigan.

3 Present address: Department of Anatomy, Harvard Medical School, Boston 15, Mass., U.S.A.
} 
cotton plug. This unit was sterilized by autoclaving and opened only to introduce the cell suspension. Six to ten milliliters of nutritive medium containing cells were used to seed the vessel, producing a fluid column $20-35 \mathrm{~mm}$ in height. By means of a motorized magnetic stirrer inverted above the culture vessel, the central teflon rod, which contained a magnetized stirring bar at its top, was rotated. This system was
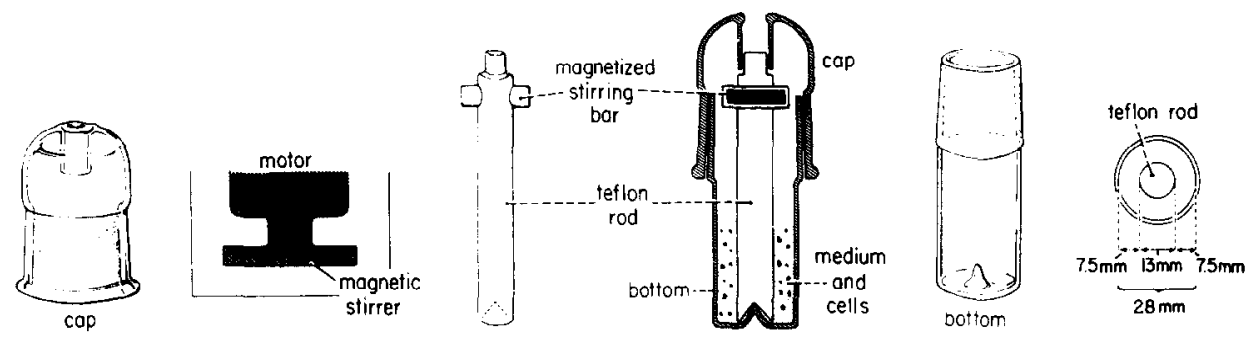

Fig. 1.-Exploded view (left), mid-sagittal view (centre) and cross sectional view (right) of the centrifugal aggregation culture vessel.

studied by $(a)$ varying the speed of rotation of the teflon rod from 150 to $450 \mathrm{rpm}$; (b) modifying the viscosity of the medium by the addition of Dextran, an inert molecule of high molecular weight $(15-20,000)$; and $(c)$ altering cell number from $2 \times 10^{5}$ to $3 \times 10^{6}$ cells $/ \mathrm{ml}$.

The principal difference between the centripetal and centrifugal aggregation techniques is shown in Fig. 2. Although in both techniques centripetally and centrifugally directed forces are operative, these forces differ in magnitude such that the resultant of these and the velocity imparted to the suspended particles differs in the two systems. In the centripetal technique, the resultant is centralizing; in the centrifugal one, it is peripheralizing.

The femoral portion of hind limbs of White Leghorn Chicken embryos of stages 38-40 [1] served as the tissue source for this investigation. The epithelium was peeled off and the skeletal element extracted, leaving a soft tissue collar of myogenic and embryonic connective tissue elements. This tissue was minced and secondarily dissociated in one of three dissociating media: GKN, a Ca-Mg-free isotonic solution of glucose, $\mathrm{KCl}$ and $\mathrm{NaCl}$ [4]; 0.02 per cent versene (ethylene dinitrilotetraacetic acid, disodium salt) in GKN and containing 0.12 per cent methylcellulose; or 0.25 per cent trypsin in GKN. All dissociating solutions contained 100 units of penicillin and $100 \mu \mathrm{g}$ of streptomycin per ml. The dissociation was conducted in $250 \mathrm{ml}$ Erlenmeyer flasks to which a magnetized stirring bar was added. The tissue mince, suspended in $100 \mathrm{ml}$ of one of the above solutions, was rotated slowly by the movement of the bar. Dissociation continued for $30 \mathrm{~min}$ or longer and at $4^{\circ}, 25^{\circ}$ or $36^{\circ} \mathrm{C}$ depending on the medium used (see results). Cells recovered from the dissociation supernatant were washed, triturated by repeated ejection from a ten milliliter pipette and suspended in nutritive medium No. 199 supplemented with 10 per cent calf serum and antibiotics. Cell viability was ascertained by the vital dye exclusion technique with erythrocin $\mathrm{B}[\mathbf{1 0 ]}$. 
The data reported in this study were obtained from thirty-three cultures incubated for $2-3$ days at $36^{\circ} \mathrm{C}$. Sample control tissues of intermediate stages in the preparation of the cultivated cells as well as all explants were fixed in Bouin's solution, embedded in paraffin and sectioned at 6 to $8 \mu$. Routine histological staining was done with Harris' hematoxylin and eosin.
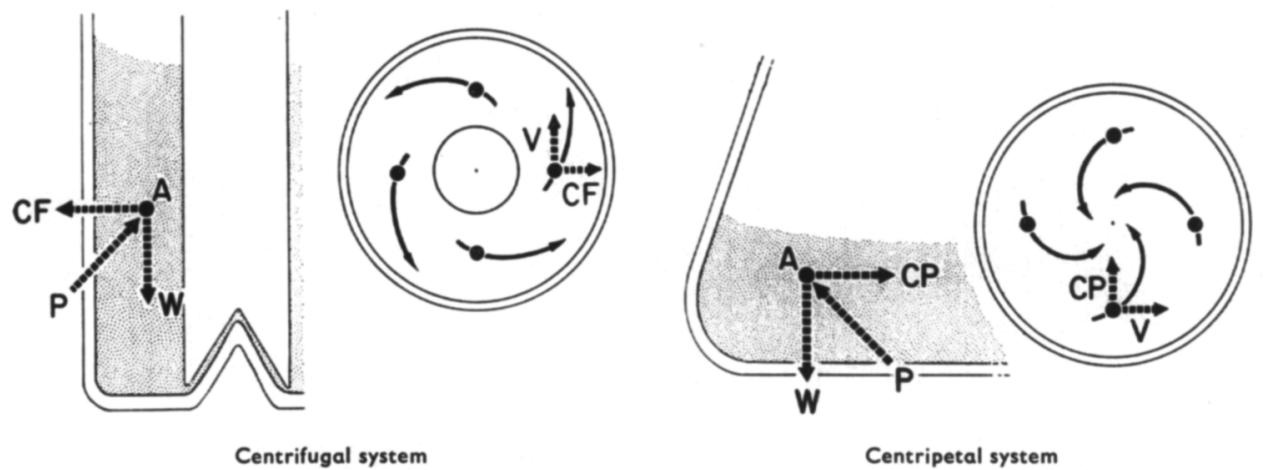

Centripetal system

Fig. 2.-Vector diagrams showing forces on a theoretical particle (A) in the centrifugal and centripetal systems. $C F$, centrifugal force; $C P$, centripetal force; $W$, gravitational force; $P$, pressure exerted by neighboring particles; $V$, velocity of medium flow.

\section{RESULTS}

Control tissues.-Microscopic examination of the intact limbs from stage 38-40 chick embryos revealed myogenic tissue organized into distinct bundles of multinucleated and elongated myotubes, separated by a loose network of interstitial embryonic connective tissue cells (Fig. 3). Muscle tissue could be differentiated from connective tissue on the basis of its more intensely eosinophilic cytoplasm. Control tissues were maintained in isotonic saline (GKN) while experimental tissues were prepared for cultivation. Degenerative changes in control tissue were attributed to cellular degeneration normally present in this tissue combined with that occurring prior to fixation.

The supernatant collected from the dissociating flask contained individual cells and small tissue fragments which were not separated during trituration (Fig. 4). An extracellular eosinophilic material surrounded the cells. The prevalence of this material varied with the dissociation medium used and also with the length of exposure to the media. Tryptic digestion for onehalf $\mathrm{hr}$ at $25^{\circ} \mathrm{C}$ produced less of this substance than found after $1 \mathrm{hr}$ at $36^{\circ} \mathrm{C}$ or after $6 \mathrm{hr}$ at $4^{\circ} \mathrm{C}$. Cellular dissociation, however, was not as complete after one-half hour's exposure. GKN treatment for up to $18 \mathrm{hr}$ produced less of this extracellular material than with trypsin at the above ex- 


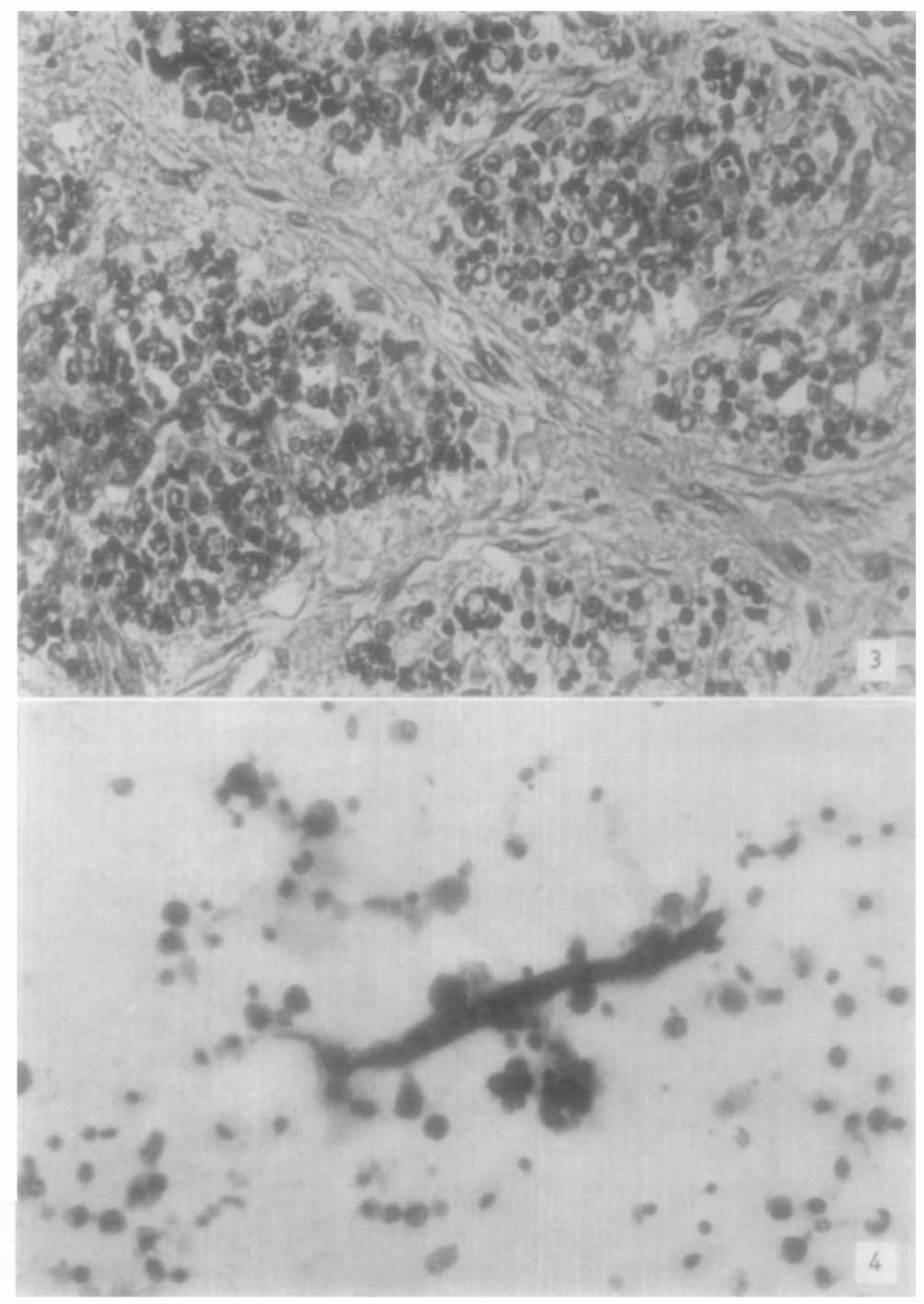

Fig. 3.-Transverse section through the intact limb musculature of a stage 40 (14 d) chick embryo. The embryonic muscle elements are organized into definite fascicles separated by connective Lissue planes. In some myolubes, darkly slaining myofibrils may be seen. The deeply eosinophilic staining properties of the myogenic tissue in contrast to the interstitial connective tissue elements is evident. Hematoxylin and eosin; $\times 350$.

Fig. 4.- Snear of cellular material recovered from the dissociation supernatant, indicating the presence of individual cells as well as small tissue fragments. This is a sample of the cell suspension used to seed all cultures. Hematoxylin and eosin; $\times 500$. 
posures, but with relatively less dissociation. The greatest degrees of disaggregation of cells in the shortest time and with the lowest appearance of the extracellular material was obtained using versene for $30 \mathrm{~min}$ at $36^{\circ} \mathrm{C}$. The possibility of injurious effects of the chelating agent upon the cell surface was reduced by the addition of 0.12 per cent methylcellulose. With versene, viability counts ranged between $70-75$ per cent following $30 \mathrm{~min}$ exposure.

Cultivated tissues.-The first gross change in the appearance of cultures maintained in constant centrifugal rotation was the formation of spherical aggregates under a $\mathrm{mm}$ in diameter. These were present at the end of one-half $\mathrm{hr}$ of cultivation and they increased in size by the gradual apposition of cells from the suspension. Eventually, a single string-shaped mass formed around the central teflon rod. This explant became continuous by wrapping around, but not adhering to, the teflon rod. A toroidal or doughnut-shaped aggregate resulted. Although initially dependent on the rotation of the teflon rod, this torus secondarily became cohesive and by the end of a $24 \mathrm{hr}$ cultivation period, when $1.5 \times 10^{5}$ cells per $\mathrm{ml}$ were used to seed the culture vessel and when the rotation rate was $300 \mathrm{rpm}$, a unified cellular torus had been constructed.

In longitudinal section, the torus was found to contain cells aligned in irregularly curved rows extending radially (Fig. 5). In transverse section and with higher magnification (Fig. 6), spindle-shaped cells or rounded cells were found grouped into bundles and separated by loosely arranged networks of stellate cells. On the basis of their acidophilia, bundled cells were identified as myogenic and those in the loose network, embryonic connective tissue. The possibility of further differentiation of these reaggregated cells was not ascertained in this study since cultures were not carried beyond three days.

The locus of torus formation around the teflon rod relative to the total height of the medium was recorded for all cultures. This position was found to be dependent on the speed of rotation and on the number of cells per ml. When total column height and cell number were constant, the explant height increased with an increase in rotation rate; when the column height and speed of rotation were held constant, explant height increased directly with an increase in cell number. The location of the torus was independent of the quantity of cell suspension cultivated.

The reliability of the centrifugal technique was tested by subjecting the system to a series of modifications. Variation in the density of the cell population, the speed of rotation or the viscosity of the cultivation medium did 
not alter the microscopic anatomy of the explants. However, alteration of the time required for cellular assemblage was noticed.

Cell population density and aggregate formation.-A series of six cultures of cell numbers ranging from $2 \times 10^{5}$ through $3 \times 10^{6}$ cells $/ \mathrm{ml}$ was maintained

TABLE I. The formation of aggregates as a function of the frequency of rotation in the centrifugal aggregation technique.

Cultures were grossly classified as (-), in which cell clumps were the size of those in the original suspension when seeded, and ( + to +++ ), as increasingly larger aggregates formed

$\left(1 \times 10^{6}\right.$ cells $\left./ \mathrm{ml}\right)$.

\begin{tabular}{cccc}
\hline & \multicolumn{3}{c}{$\begin{array}{c}\text { Gross appearance of explant at } \\
\text { rotational frequency of }\end{array}$} \\
\cline { 3 - 4 } $\begin{array}{c}\text { Cultivation } \\
\text { time (hr) }\end{array}$ & $150 \mathrm{rpm}$ & $300 \mathrm{rpm}$ & $450 \mathrm{rpm}$ \\
\hline 0 & - & - & - \\
1 & ++ & + & - \\
5 & +++ & ++ & + \\
8 & Torus & +++ & ++ \\
12 & Torus & Torus & +++ \\
16 & Torus & Cohesive & Cohesive \\
& torus & torus \\
24 & Cohesive & Cohesive & Cohesive \\
& torus & torus & torus \\
\hline
\end{tabular}

for $48 \mathrm{hr}$ at $300 \mathrm{rpm}$. The formation of aggregates was observed grossly at $12 \mathrm{hr}$ intervals. A unified explant was not found in the culture of $2 \times$ $10^{5}$ cells $/ \mathrm{ml}$ even after $48 \mathrm{hr}$. Only small clumps, slightly larger than those of the original suspension, were seen at the termination of the cultivation period. In contrast, formed doughnut-shaped explants appeared in cultures of $4 \times 10^{5}, 6 \times 10^{5}, 8 \times 10^{5}, 1 \times 10^{6}$ and $2 \times 10^{6}$ cells $/ \mathrm{ml}$. Large spherical aggregates were present in the culture of $3 \times 10^{6}$ cells $/ \mathrm{ml}$ after $12 \mathrm{hr}$, but confluence of these into a torus was not apparent until after $24 \mathrm{hr}$.

Fig. 5.-Longitudinal section of a portion of a torus from the centrifugal aggregation technique. The torus was transected (cut end shown) to remove it from the teflon rod. The original inner surface (adjacent to the teflon rod) is the inferior border in the field. Hematoxylin and eosin; $\times 140$.

Fig. 6.-Transverse section through a torus from the centrifugal aggregation technique, showing the grouping of cells into closely compacted bundles separated by loosely arranged cells. Hematoxylin and eosin; $\times 450$. 

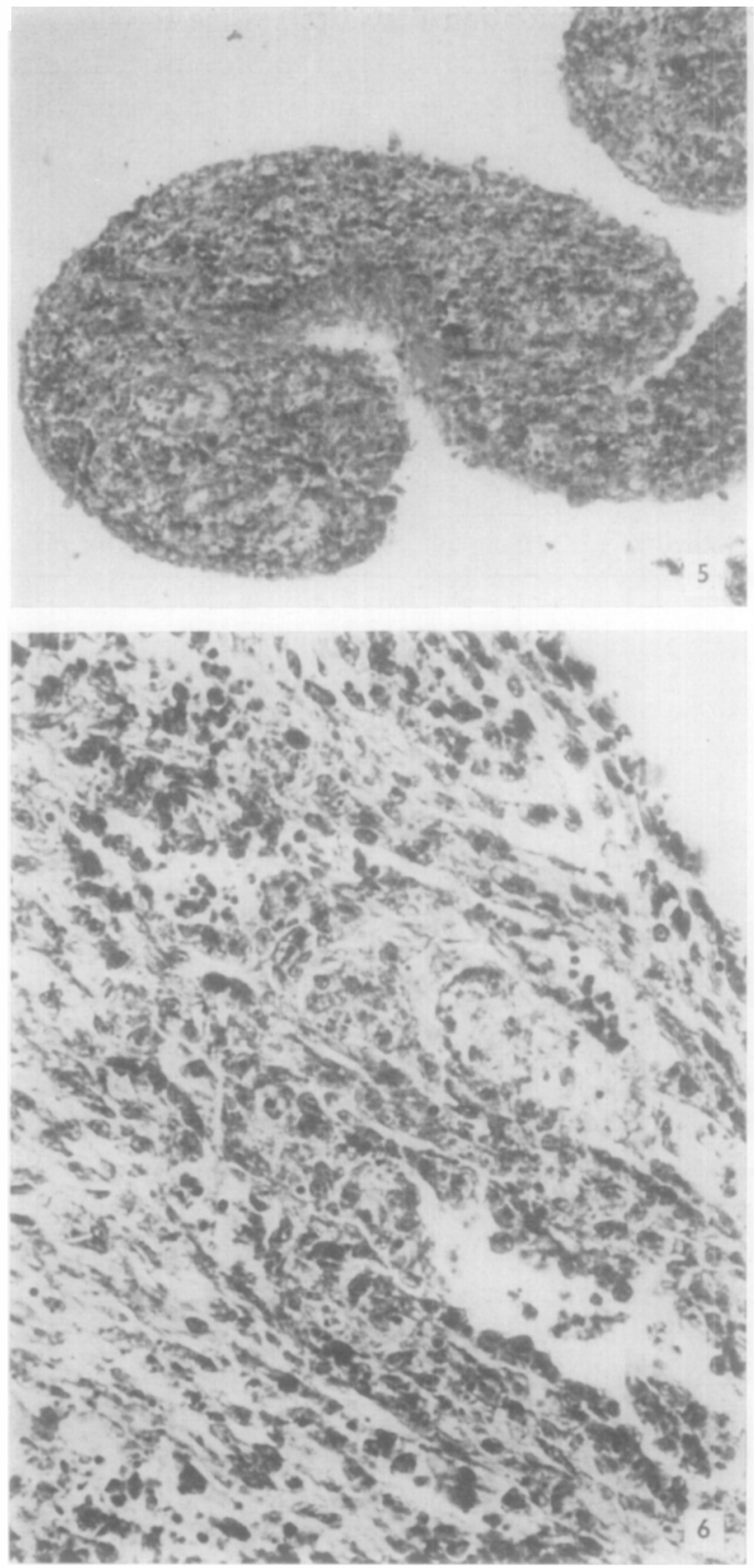
A wide range of cell population densities suffice for the formation of the toroidal explant in this system. However, a minimum cell number is needed for the formation of a unified explant and above a certain density the time required for aggregation is prolonged.

TABLE II. The formation of aggregates in solutions of varied viscosity in the centrifugal aggregation technique.

Cultures were grossly classified as $(-)$, in which cell clumps were the size of those in the original suspension when seeded, and $(+$ to $t+t)$ as increasingly larger aggregates formed $\left(3 \times 10^{6}\right.$ cells/ml; $300 \mathrm{rpm})$.

\begin{tabular}{cccc}
\hline & \multicolumn{3}{c}{$\begin{array}{c}\text { Gross appearance of explant with } \\
\text { concentration of Dextran of }\end{array}$} \\
\cline { 2 - 4 } $\begin{array}{c}\text { Cultivation } \\
\text { time (hr) }\end{array}$ & $0 \mathrm{mg} / \mathrm{ml}$ & $4 \mathrm{mg} / \mathrm{ml}$ & $12 \mathrm{mg} / \mathrm{ml}$ \\
\hline 0 & - & - & - \\
2 & ++ & + & - \\
7 & ++ & + & - \\
14 & +++ & ++ & + \\
24 & Torus & +++ & ++ \\
38 & Torus & Torus & ++ \\
48 & Cohesive & Cohesive & Cohesive \\
& torus & torus & torus \\
\hline
\end{tabular}

Speed of rotation and aggregate formation.-In three simultaneous cultures of $1 \times 10^{6}$ cells $/ \mathrm{ml}$, the rotation frequency was set at 150,300 and $450 \mathrm{rpm}$. Cultivation was conducted for $24 \mathrm{hr}$ which was sufficient for aggregation at $300 \mathrm{rpm}$ as described above. The cultures were observed after $1 \mathrm{hr}$ and at approximately $4 \mathrm{hr}$ intervals thereafter. Cohesiveness of the torus was established when it did not disintegrate consequent to halting the rotation of the central rod. All explants were found to re-form at their previous loci on the central bar shortly after rotation was resumed.

As seen in Table I, all rotation speeds resulted in the formation of a toroidal explant. However, with heightened frequency, (1) the increase in size of the original spherical aggregates was delayed and consequently (2) the fusion of these initial clusters into a single toroidal aggregate was retarded, but (3) the time required for the establishment of the cohesiveness of the torus was reduced.

Culture medium viscosity and aggregate formation.-A series of three cultures was conducted, wherein increasing concentrations of Dextran were added 
to the nutritive medium to alter the viscosity. Cultures of $3 \times 10^{6}$ cells $/ \mathrm{ml}$ were maintained at $300 \mathrm{rpm}$ for $48 \mathrm{hr}$ during which time the gross character of the cultures was recorded as shown in Table II.

Despite alterations in viscosity, toroidal explants were generated in all cultures. Increased viscosities, however, temporarily hindered the aggregation of cells but once a torus was established, cohesion was more rapidly acquired in solutions of high viscosity.

\section{DISCUSSION}

Cellular reaggregation, as effected with the centrifugal technique, yields a toroidal explant. Three phases in the formation of this cxplant are evident: First, there is the adhesion of cells to form small spherical aggregates; then, these coalesce into an unstable and rotation-dependent torus; finally, this unstable aggregate becomes cohesive and retains its integrity when the rotation of the fluid medium ceases.

Such secondary acquisition of firm cellular attachment has been observed with mammalian cell lines cultivated in the centripetal aggregation system [9]. This initial period of unstable adhesion in both the centrifugal and centripetal techniques might be explained by the mechanism of cellular reaggregation as seen in the electron microscope [3]. Accordingly, reaggregating cells make initial tenuous contacts via surface undulations and microvilli. Subsequently, their cell membranes become parallel to one another and a more stable intercellular adhesion is formed.

The delayed production of a cohesive torus is also in agreement with the theory of specific adhesion proposed by Holtfreter [4] and supported by Moscona $[6,7,8]$ and Steinberg $[13]$. The change from an unstable association of cells to a more stable one might represent the sorting out of cells from an original non-selective attachment to a selective association of similar cell types.

Modification of the centrifugal aggregation technique reveals that the viscosity, the cell population density and the speed of rotation of the cultivated suspension are all important determinants of aggregate formation. In the presence of culture media of increased viscosity, the initial assemblage of cells is temporarily retarded. Such might be expected since one would have to exert a greater effort to approximate two gross spherical bodies immersed in a highly viscous medium than in a medium of lower viscosity. It follows that any two cells coming together in a fluid medium of low viscosity would do so with greater frequency than if in a highly viscous medium. Since inter- 
cellular contact is undoubtedly a prerequisite for adhesion, and assuming no mechanism for increasing the range of action of intercellular forces, the speed of aggregation would be less in the presence of heightened viscosity.

A mechanism for the impedance of cellular assemblage with increased cell population density is suggested by the theory of specific adhesion. In a densely-populated culture, any one cell would tend to contact and adhere to a greater number of cells non-specifically. More surface per cell would be in contact with unlike cells and consecfuently more non-specific contacts would have to be broken than in a less dense population. The effect of this would be to delay specific adhesion of cells and establishment of a cohesive aggregate.

Torus formation in the centrifugal system is delayed with increased speeds of rotation. A similar diminution in cellular assemblage with increased rotation has been described for the centripetal system 8 l. In both techniques, an increase in rotation rate probably increases cellular agitation which disrupls the adhesion of cells and thereby retards the formation of aggregates.

\section{SUMMARY}

A technique for the reaggregation of dissociated cells in a centrifugallyrotating medium is reported. Myogenic and embryonic connective tissue cells cultivated in this system organize into a single toroidal explant. Histologically, this aggregate contains bundles of pre-muscle cells separated by connective tissue. Cell aggregability with this technique is retarded by decreasing rotation frequency and cell number, but accelerated by decreasing medium viscosity.

The contrasting character of the physical forces associated with this system as well as the comparable results obtained from it suggest the concomitant application of the centrifugal aggregation technique with the centripetal aggregation technique in future reaggregative studies.

Sincere appreciation is extended to Dr Raymond $\mathrm{H}$. Kahn for his guidance of this investigation and for his helpful counsel during the preparation of this manuscript. 


\section{REFERENCES}

1. Hamburger, V. and Hamilton, H. L., J. Morphol. 88, 49 (1951).

2. Holtfreter, J., Arch. Exptl Zellforsch. 23, 169 (1939).

3. Lessers, R. J., J. Exptl Zool. 153, 171 (1963).

4. Merchant, D. J., Kahn, R. H. and Murphy, W. H., Jr., Handbook of Cell and Organ Culture. Burgess, Minneapolis, Minnesota, 1960.

5. Moscona, A., in D. Rudnick (ed.), Developing Cell Systems and Their Controls. Ronald Press, New York, 1960.

6. - Nature (London) 190, 408 (1961).

7. — Exptl Cell Res. 22, 455 (1961).

8. - J. Cellular Comp. Physiol. 60, 65 (1962).

9. Moscowirz, M., Nature (London) 200, 854 (1963).

10. Phillips, H. J. and Terryberry, J. E., Exptl Cell Res. 13, 341 (1957).

11. Steinberg, M. S., Proc. Natl Acad. Sci. USA 48, 1577 (1962).

12. — Science 137, 762 (1962).

13. — Proc. Natl Acad. Sci. USA 48, 1769 (1962). 